\title{
Unexpected Foreign Body induced refracted Maxillary Sinusitis
}

Bassel Hallak ${ }^{1}$, Jean-Pierre Bühler ${ }^{1}$, and Salim Bouayed ${ }^{1}$

${ }^{1}$ Sion Hospital Valais Romand Hospital Center

January 5, 2021

\begin{abstract}
Foreign bodies' impact in paranasal sinuses are unusual clinical conditions and most often occur in the maxillary sinus. Odontogenic sources induce maxillary sinusitis in approximately 10 to $12 \%$ of cases. Iatrogenic dental manipulation is the most common cause of foreign bodies' impaction in the maxillary sinus.
\end{abstract}
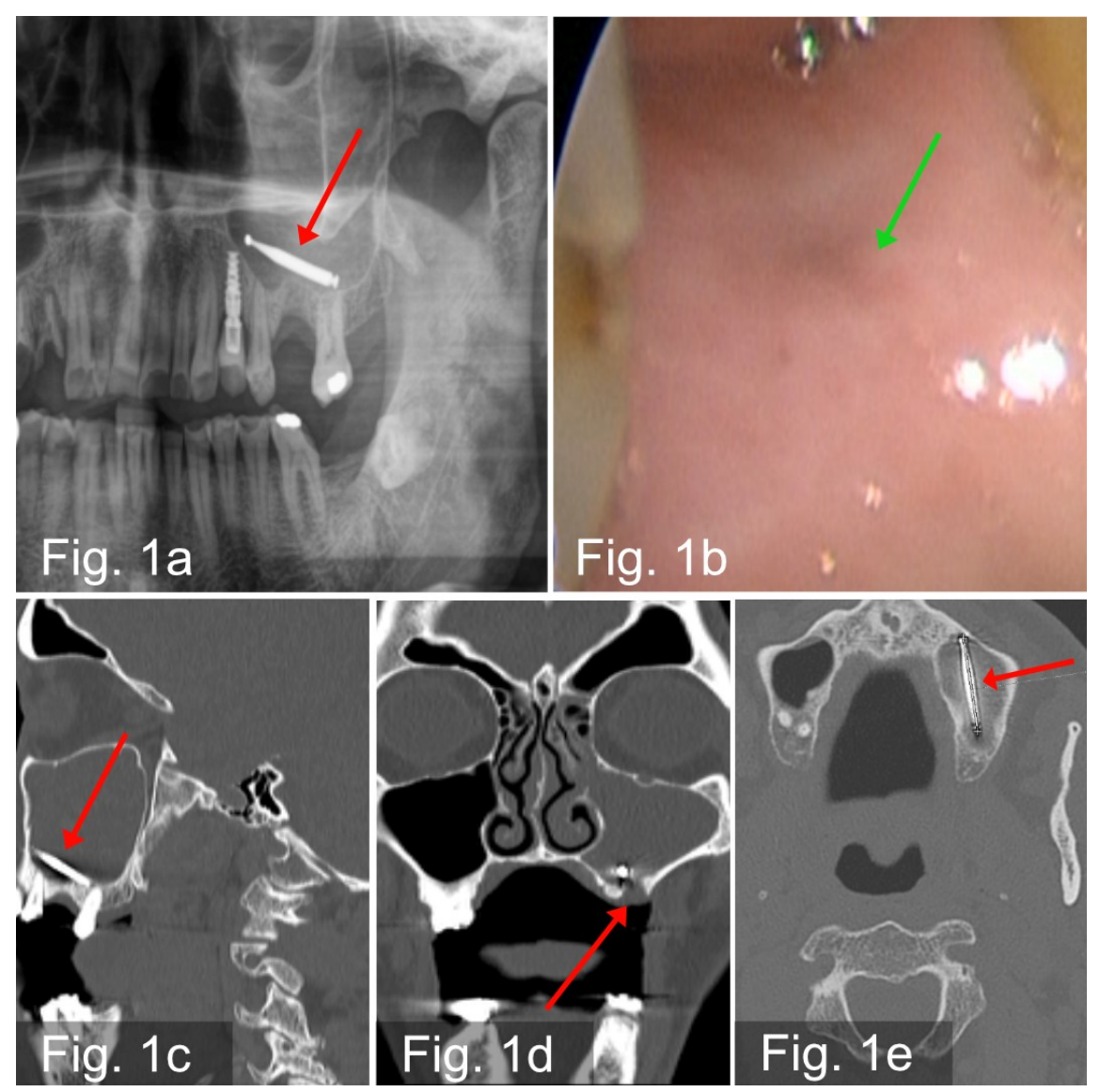


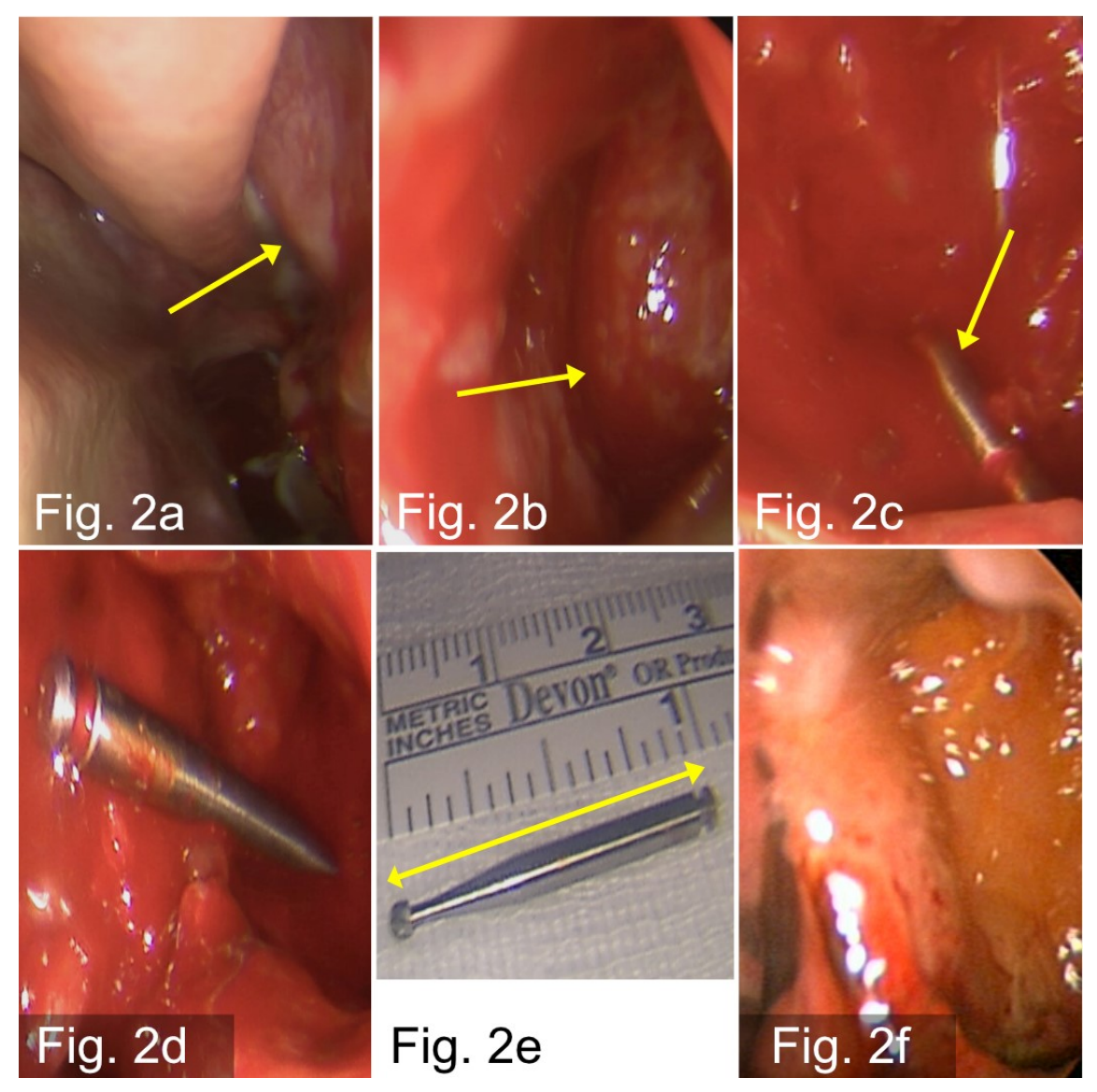

